\title{
Purification and Phytotoxicity of Apicidins Produced by the Fusarium semitectum KCTC16676
}

\author{
Jianming Jin ${ }^{1}$, Seung-Ryel Baek ${ }^{1}$, Kyung-Rim Lee ${ }^{2}$, Jungkwan Lee ${ }^{1}$, Sung-Hwan Yun ${ }^{3}$, Seogchan Kang ${ }^{4}$ and \\ Yin-Won Lee ${ }^{1 *}$ \\ ${ }^{1}$ Department of Agricultural Biotechnology and Center for Agricultural Biomaterials, Seoul National University, Seoul 151-921, \\ Korea \\ ${ }^{2}$ Department of Biology, University of Incheon, Incheon 402-749, Korea \\ ${ }^{3}$ Department of Medical Biotechnology, Soonchunghyang University, Asan 336-745, Korea \\ ${ }^{4}$ Department of Plant Pathology, The Pennsylvania State University, University Park, PA 16802, USA \\ (Received on August 28, 2008; Accepted on November 6, 2008)
}

\begin{abstract}
Apicidin is a cyclic tetrapeptide produced by some Fusarium species and is known to inhibit Apicomplexan histone deacetylase. The goals of this study were to determine species identity of Fusarium isolate KCTC16676, an apicidin producer, to improve a method for apicidin extraction, and to test phytotoxicity of apicidin and its analogs. We compared sequences of the translation elongation factor 1-alpha (TEF) gene in KCTC16676 with those from isolates representing diverse Fusarium species, which showed that KCTC16676 belongs to the $F$. semitectum-F. equiseti species complex. To enhance apicidin production, after culturing isolate KCTC16676 on a wheat medium for 3 weeks at $25^{\circ} \mathrm{C}$, the culture was extracted with chloroform. Apicidins were purified through a reverse phase $C_{18}$ silica gel column, resulting in $5 \mathrm{~g}$ of apicidin, $200 \mathrm{mg}$ of apicidin A, and $300 \mathrm{mg}$ of apicidin $D_{2}$ from $4 \mathrm{~kg}$ of wheat cultures; this represents a significant yield improvement from a previous method, offers more materials to study the modes of its action, and facilitates the elucidation of the apicidin biosynthesis pathway. Apicidin and apicidin $\mathrm{D}_{2}$ showed phytotoxicity on both seedlings and 2-week-old plants of diverse species, and weeds were more sensitive to apicidins than vegetables
\end{abstract}

Keywords : apicidin, Fusarium semitectum, hemorrhagic factor, mycotoxin

The genus Fusarium is widely distributed in soil, aerial plant parts, plant debris, and other organic substrates, and can cause diseases in plants, humans, and domesticated animals (Leslie and Summerell, 2006). In addition, Fusarium spp. produce many secondary metabolites that are associated with plant disease, cancer and other growth defects in humans and animals (Desjardines, 2006). Some of the

\footnotetext{
*Corresponding author.

Phone) +82-2-880-4671, FAX) +82-2-873-2317

E-mail)lee2443@snu.ac.kr
}

Fusarium secondary metabolites have been used commercially as plant and animal growth promoters (Leslie and Summerell, 2006).

Fusarium taxonomy has been plagued by rapidly changing species concepts, ranging from 9 to 1,000 species depending on the species concepts employed (Summerell et al., 2003). Although taxonomy based on the morphological species concept (Gerlach and Nirenberg, 1982; Nelson et al., 1983) was widely accepted, it failed to differentiate certain species due to their morphological complexity. Biological (Leslie, 2001) and phylogenetic (Nirenberg and O'Donnell, 1998) species concepts have also been applied, which in some situations better resolve taxonomic questions.

Apicidin is a cyclic tetrapeptide consisting of cyclo- $\{\mathrm{L}-$ $N$-methoxyltryptophan-L-isoleucyl-D-pipecolinyl-L-(2amino-8-oxodecanoyl)\} (Fig. 1; Singh et al., 1996). Apicidin contains classical electrophilic keto group, and the

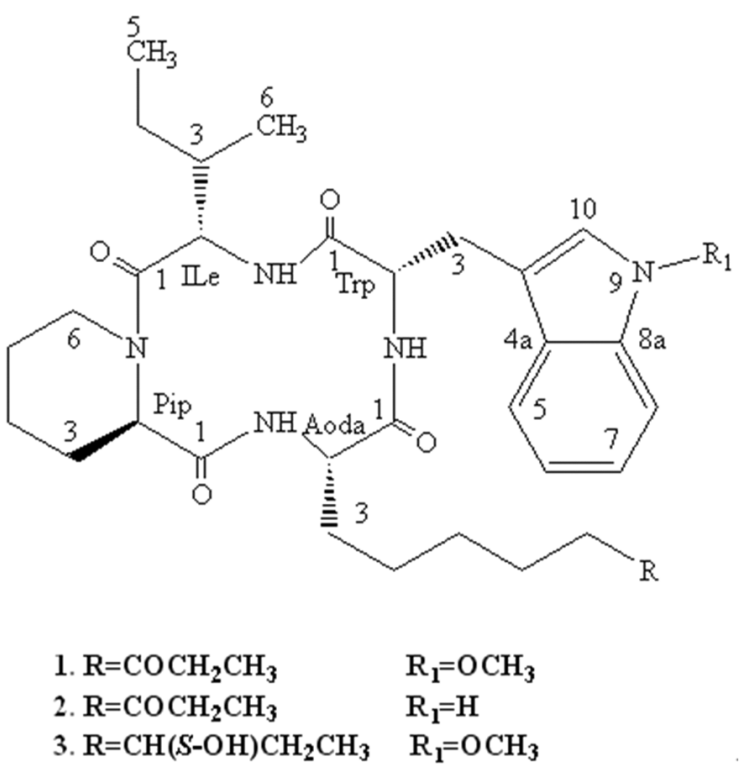

Fig. 1. Structure of apicidin (1), apicidin A (2), and apicidin $D_{2}$ (3). 
cyclic nature of the peptide is critical for its biological activity (Singh et al., 2002). Apicidin exhibits potent, broad spectrum antiprotozoal activity in vivo against Apicomplexan parasites. Antiprotozoal activity of apicidin results from the inhibition of histone deacetylase, a key nuclear enzyme involved in transcriptional control (Darkin-Rattray et al., 1996). Apicidin also has showed anti-growth activity in HeLa cells, human endometrial cells and ovarian cancer cells (Hong et al., 2003; Ueda et al., 2007).

Several fungal cyclic tetrapeptides such as HC-toxin (Kawai et al., 1983; Liesch et al., 1982), Cly-1 (Takayama et al., 1984), and Cly-2 (Hirota et al., 1973) have been shown to be phytotoxic. These cyclic peptides, which were isolated from various fungal species, exhibit structures similar to that of apicidin. Phytotoxicity of apicidin was assayed on duckweed (Lemna pausicostata L.) in which apicidin resulted in disruption of plant cell membrane as well as the inhibition of histone deacetylase (Abbas et al., 2001). In addition, many organelles in apicidin-treated tissues appear less distinct, and chloroplasts contain larger starch grains than that of the control (Abbas et al., 2001).

We previously reported apicidin production by Fusarium sp. KCTC16676 and toxicity of apicidin in rat, brine shrimp and human tumor cells (Park et al., 1999). In that study, the species identity of strain KCTC16676 was not resolved due to its morphological ambiguity and phytotoxicity of apicidin on various plants was not tested due to the small amount of apicidin produced. Here, we characterized the species identity of KCTC16676 strain using a gene sequence, enhanced the extraction procedure to increase apicidin production, and tested phytotoxicity of apicidins on several plant species.

\section{Materials and Methods}

Strain and culture conditions. Fusarium strain KCTC16676 was originally isolated from soybean seeds (Park et al., 1999). The strain was stored in $25 \%$ glycerol at $-70^{\circ} \mathrm{C}$ and revitalized on potato dextrose agar (PDA) as needed. For genomic DNA extraction, it was grown in $50 \mathrm{ml}$ of liquid complete medium (CM; Leslie and Summerell, 2006) in 250-ml Erlenmeyer flasks at $25^{\circ} \mathrm{C}$ for 3 days on a rotary shaking incubator at $150 \mathrm{rpm}$, and mycelia were harvested and lyophilized. For apicidin production, Erlenmeyer flasks $(1 \mathrm{~L})$ containing $200 \mathrm{~g}$ of wheat and $120 \mathrm{ml}$ of deionized water were autoclaved at $121^{\circ} \mathrm{C}$ for $1 \mathrm{~h}$. Agar blocks of KCTC16676 grown on PDA for 3 days were inoculated on the wheat medium, and the cultures were incubated for 3 weeks at $25^{\circ} \mathrm{C}$. The cultures were air-dried for 5 days in a ventilated hood and were ground to the consistency of flour.

Polymerase chain reaction $(\mathrm{PCR})$ and sequencing. $\mathrm{A}$ standard PCR protocol was used to amplify the translation elongation factor 1-alpha (TEF) gene region. TEF-F (5'ATGGGTAAGGARGACAAGAC-3') and TEF-R (5'-GGARGTACCAGTSATCATGTT-3') primers were used for PCR, with an annealing temperature of $53^{\circ} \mathrm{C}$ (O'Donnell et al., 1998). Oligonucleotides were synthesized by Bioneer Corporation (Chungwon, Korea), dissolved at $100 \mu \mathrm{M}$ in sterile water, and stored at $20^{\circ} \mathrm{C}$. PCR product was purified using the Geneclean Turbo Kit (Qbiogene, Irvine, CA, USA) and cloned into a pGEM-T Easy Vector (Promega, Madison, WI, USA) for sequencing. DNA sequencing was performed using an automated sequencer (ABI Prism 3700; Applied Biosystem, Foster, CA, USA) at the National Instrumentation Center for Environmental Management (Seoul National University, Seoul, Korea). The TEF gene sequences of KCTC16676 were used to compare with the TEF sequences archived in FUSARIUM-ID v.1.0 (http:// fusarium.cbio.psu.edu; Geiser et al., 2004). Its sequences were aligned with TEF sequences of $23 \mathrm{~F}$. semitectum and F. equiseti complexes with the CLUSTAL W program (Thompson et al., 1994) with default parameters. A phylogenetic tree was constructed using the neighbor-joining method (Saitou and Nei, 1987) with a Kimura-two parameter nucleotide substitution model in the MEGA3.1 program (Kumar et al., 2004). Bootstrap analyses were performed with 2000 replicates.

\section{Survey of apicidin production among Fusarium species.} The production of apicidin among isolates in the $F$. semitectum-F. equiseti species complex grown in the wheat culture was investigated using the protocol of Park et al. (1999) with a slight modification. A 20-g portion of each culture was extracted with $100 \mathrm{ml}$ of chloroform for 30 min. After filtration through Whatman no. 2 filter paper, the filtrate was dried. The residue was dissolved in $2 \mathrm{ml}$ of chloroform and applied to a Florisil column $(2 \mathrm{~cm}$ [inside diameter] by $20 \mathrm{~cm}$ ). The column was packed with $10 \mathrm{~g}$ of Florisil (60 to 100 mesh) topped with $5 \mathrm{~g}$ of anhydrous sodium sulfate. After washing with $100 \mathrm{ml}$ of $n$-hexane, $100 \mathrm{ml}$ of chloroform-methanol (3:1, vol/vol) was applied to the column for elution. After drying the eluate, it was redissolved in $2 \mathrm{ml}$ of methanol and was analyzed using high-performance liquid chromatography (HPLC). For the HPLC analysis, a Shimadzu LC-10AD equipped with Shimadzu APD-10A detector (Shimadzu, Kyoto, Japan) was used. The column was a Symmetry $\mathrm{C}_{18}$ column (4.6× $150 \mathrm{~mm}$; Waters, Milford, MA, USA); UV=291 nm; the mobile phase was aqueous methanol; flow rate was $0.2 \mathrm{ml} /$ $\min$.

Purification of apicidins. Wheat cultures of KCTC16676 (4 kg) were extracted three times with chloroform (total of 
17 liters), and the combined extracts were concentrated under reduced pressure. The concentrated chloroform extract was dissolved in $300 \mathrm{ml}$ of distilled water and was defatted with $300 \mathrm{ml}$ of $n$-hexane. The water fraction was extracted with $300 \mathrm{ml}$ of chloroform, and the chloroform fraction was applied to a silica gel column $(60 \times 750 \mathrm{~mm})$ and eluted with ethyl acetate-hexane (3:1, v/v). Each fraction was screened for apicidins by thin-layer chromatography (TLC), and fractions containing apicidin were combined and concentrated. TLC with pre-coated silica gel (Merck, Darmstadt, Germany) was used, and detection of apicidin was accomplished by spraying the plates with $5 \%$ $\rho$-anisaldehyde-sulfuric acid followed by heating as previously described (Park et al., 1999). The partially purified fraction was passed through silica gel $(50 \times 600$ $\mathrm{mm}$ ) followed by a reverse phase $\mathrm{C}_{18}$ silica gel column $(30 \times 300 \mathrm{~mm})$.

Phytotoxicity of apicidins on plant seedlings. Six plant species, cucumber (Cucumis sativus L.), tomato (Lycopersicon esculentum Mill.), lettuce (Lactuca sativa L.), maize (Zea mays L.), wheat (Triticum aestivum L.) and soybean (Glycine max L.), were tested for their sensitivity to apicidin and apicidin $\mathrm{D}_{2}$. Seeds were soaked in $1 \% \mathrm{NaClO}$ for $10 \mathrm{~min}$ to eliminate seedborne fungi, and then washed with sterile distilled water for three times. Apicidin or apicidin $\mathrm{D}_{2}$ was added to $2 \%$ water agar in glass test tubes autoclaved at $121^{\circ} \mathrm{C}$ for $20 \mathrm{~min}$. Water agar without apicidins served as a negative control. Each seed was planted in the test tube sealed with a cotton plug. The tubes were placed in a growth chamber (Model EF7, Conviron, Winnipeg, Canada) for 14 days, set at a cycle of $14 \mathrm{~h}$ in light at $26^{\circ} \mathrm{C}$ and $10 \mathrm{~h}$ in dark at $18^{\circ} \mathrm{C}$ with $75 \%$ relative humidity. After 14 days, length and dry weight of plants (dried at $60^{\circ} \mathrm{C}$ for 2 days) were measured. This assay was performed twice with triplicates. The inhibition of plant growth by apicidin and apicidin $\mathrm{D}_{2}$ was evaluated using the following formula: Growth inhibition $(\%)=\left[\left(\right.\right.$ Growth $_{\text {control }}-$ Growth $\left._{\text {test }}\right) /\left(\right.$ Growth $\left.\left._{\text {control }}\right)\right] \times 100$, where Growth $_{\text {control }}=$ mean of growth of the control seedlings, Growth $\mathrm{test}=$ mean of growth of the test seedlings. Minus sign indicates that growth of the seedling was not inhibited compared with the control. T test (LSD) was performed to evaluate phytotoxic effects of apicidin and apicidin $\mathrm{D}_{2}$ with SAS statistical software version 6.04 (SAS Institute, Cary, NC, USA).

Phytotoxicity of apicidins on weeds and vegetable plants. Jimsonweed (Datura stramonium L.), wild spinach (Chenopodium amaranticolor L.), cucumber (Cucumis sativus L.) and tomato (Lycopersicon esculentum Mill.) were tested for sensitivity to apicidin and apicidin $D_{2}$. Seeds were planted individually in a commercial potting mixture supplemented with a slow release fertilizer (N-P-K, 14:14: $14)$ and placed in a greenhouse. The greenhouse temperature was maintained at $28-32^{\circ} \mathrm{C}$ with $40-60 \%$ relative humidity. Two concentrations of apicidin and apicidin $\mathrm{D}_{2}$ $(10$ and $20 \mu \mathrm{g} / \mathrm{ml})$ dissolved in $1 \%$ methanol were used for the test. Two week-old plants (three to four-leaf stage including cotylendon) were sprayed with each toxin preparation $(5 \mathrm{ml})$ using an aerosol sprayer. Distilled water containing $1 \%$ methanol was used as a negative control. After toxin application, plants were maintained for 14 days in the greenhouse and observed for phytotoxic symptoms such as chlorosis, necrosis, leaf rolling, stunting, and mortality during the observation period. After 14 days, height of the aboveground part was measured. This assay was performed twice with triplicates.

\section{Results and Discussion}

Identification of strain KCTC16676. We sequenced a 667-bp TEF fragment amplified from KCTC16676, and searched FUSARIUM-ID v.1.0 (http://fusarium.cbio.psu. edu; Geiser et al., 2004) using the resulting sequence as a query. The TEF sequence of KCTC16676 showed high identity with those of the isolates in F. pallidoroseum $(=F$. semitectum; 90\%), F. scirpi (91\%) and F. equiseti (92-93\%). We analyzed the phylogenetic position of KCTC16676 relative to $23 F$. semitectum and $F$. equiset $i$ isolates using the neighbor-joining method, which showed that KCTC16676 belongs to the $F$. semitectum-F. equiseti species complex (Fig. 2).

Although the $F$. semitecum-F equiseti species complex has not yet been well delineated phylogenetically (D. Geiser, personal communication), two species can be differentiated morphologically. The shape of $F$. semitectium macroconidia is curved and tapering to a point at apical cells and is slender with a curved dorsal surface and a straighter ventral surface, while that of $F$. equiseti is elongated at apical cells and is curvature at both dorsal and ventral surface (Leslie and Summerell, 2006). The curved, pointed apical cells of KCTC16676 resembled those of $F$. semitectum and $F$. sambucinum, but other features, such as the rapid growth at $30^{\circ} \mathrm{C}$ and chemotype, are not typical of $F$. sambucinum (Park et al., 1999). Based on both of the phylogenetic and morphological characteristics, we tentatively identified that the strain is F. semitectum.

Enhancement of apicidin production by KCTC16676 strain. Air-dried wheat cultures of KCTC16676 strain were extracted with chloroform. Through silica gel and reversephase $\mathrm{C}_{18}$ column, apicidin and two known analogs, apicidin $A$ and apicidin $D_{2}$, were purified. We purified $5 \mathrm{~g}$ of apicidin, $200 \mathrm{mg}$ of apicidin $\mathrm{A}$, and $300 \mathrm{mg}$ of apicidin $\mathrm{D}_{2}$ 


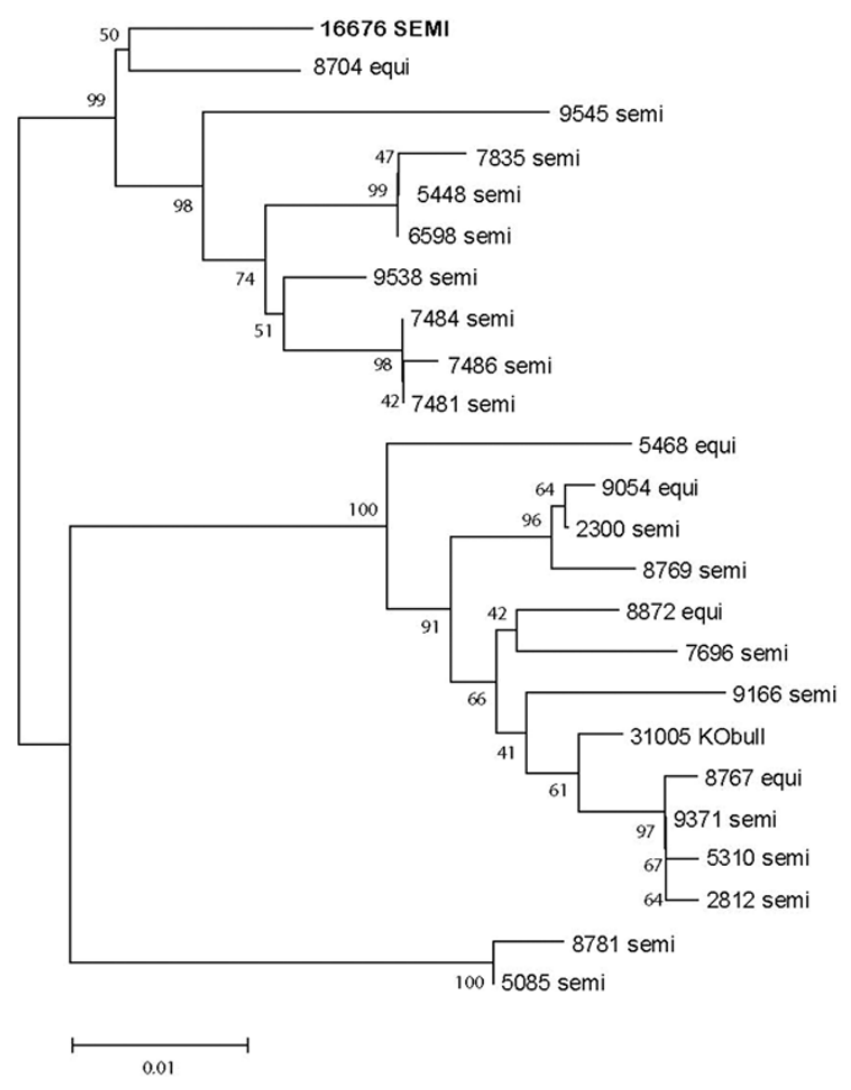

Fig. 2. Dendrogram showing the phylogenetic framework based on the TEF gene sequences of strain KCTC16676 and 23 isolates belonging to the $F$. semitectum- $F$. equiseti species complex. A phylogenetic tree was constructed using the neighbor-joining method with a Kimura-two parameter nucleotide substitution model in the MEGA3.1 program (Kumar et al., 2004). Bootstrap analyses were performed with 2000 replicates. 16676SEMI indicates KCTC16676; semi indicates $F$. semitectum strains; equi indicates $F$. equiseti strains; KObull indicates $F$. semitectum strain.

from $4 \mathrm{~kg}$ of wheat cultures.

We previously purified apicidin from the ethyl acetate extract of wheat culture of KCTC16676 through normal phase columns, Florisil and Silica gel (Park et al., 1999). In this study, we used chloroform instead of ethyl acetate for apicidin extraction because the chloroform extract contained less pigments than the ethyl acetate extract. The average amount of apicidin purified from wheat cultures was 0.3 $\mathrm{mg} / \mathrm{g}$ in the previous study, whereas in this study, it was 1.3 $\mathrm{mg} / \mathrm{g}$. We also found that using the reverse $\mathrm{C}_{18}$ column was efficient to remove the pigments in the culture extracts and to separate apicidin from its anlalogs, apicidin A and apicidin $\mathrm{D}_{2}$.

The production of apicidin is not common amongst Fusarium spp. We previously screened for apicidin production among 52 isolates from 20 soybean samples, representing 7 Fusarium spp. and found only two apicidinproducing strains, KCTC16676 and 16677 (Park et al.,
1999). We checked for apicidin production among additional 23 isolates belonging to the $F$. semitectum-F. equseti complex in this study, but no strains produced apicidin, suggesting that the ability to produce apicidin is not widely distributed among Fusarium spp., even among isolates in the F. semitectum-F. equseti complex.

Phytotoxicity of apicidins on plant seedlings. At $5 \mu \mathrm{g} / \mathrm{ml}$ apicidin, seedlings of most plants were not visibly inhibited. Only root length of maize and root dry weight of lettuce were significantly affected (Table 1). At $10 \mu \mathrm{g} / \mathrm{ml}$ of apicidin, the length and dry weight of shoot in all plants were significantly reduced. Root dry weight of all plants

Table 1. Effects of apicidin and apicidin $\mathrm{D}_{2}$ on seedling growth of six plant species

\begin{tabular}{lcccccc}
\hline \hline & \multicolumn{3}{c}{ Apicidin $(\mu \mathrm{g} / \mathrm{ml})$} & \multicolumn{3}{c}{ Apicidin $\mathrm{D}_{2}(\mu \mathrm{g} / \mathrm{ml})$} \\
\cline { 2 - 7 } & 5 & 10 & 20 & 5 & 10 & 20 \\
\hline Shoot length & (\% of growth inhibition) & & & \\
Maize & $5 \mathrm{a}^{\dagger}$ & $23 \mathrm{~b}$ & $70 \mathrm{ab}$ & $-38 \mathrm{c}$ & $3 \mathrm{bc}$ & $54 \mathrm{~b}$ \\
Cucumber & $-2 \mathrm{a}$ & $51 \mathrm{a}$ & $58 \mathrm{c}$ & $-16 \mathrm{~b}$ & $-8 \mathrm{c}$ & $16 \mathrm{c}$ \\
Lettuce & $21 \mathrm{a}$ & $21 \mathrm{~b}$ & $51 \mathrm{c}$ & $25 \mathrm{a}$ & $40 \mathrm{a}$ & $55 \mathrm{~b}$ \\
Soybean & $8 \mathrm{a}$ & $25 \mathrm{ab}$ & $74 \mathrm{a}$ & $-3 \mathrm{~b}$ & $26 \mathrm{ab}$ & $78 \mathrm{a}$ \\
Tomato & $3 \mathrm{a}$ & $43 \mathrm{ab}$ & $73 \mathrm{a}$ & $-4 \mathrm{~b}$ & $33 \mathrm{a}$ & $56 \mathrm{~b}$ \\
Wheat & $11 \mathrm{a}$ & $27 \mathrm{ab}$ & $61 \mathrm{bc}$ & $11 \mathrm{a}$ & $22 \mathrm{ab}$ & $55 \mathrm{~b}$
\end{tabular}

Shoot dry weight ( $\%$ of growth inhibition)

$\begin{array}{lcccccc}\text { Maize } & 22 \mathrm{a} & 22 \mathrm{a} & 86 \mathrm{a} & -12 \mathrm{bc} & 27 \mathrm{a} & 79 \mathrm{a} \\ \text { Cucumber } & -8 \mathrm{a} & 27 \mathrm{a} & 34 \mathrm{c} & -28 \mathrm{c} & -9 \mathrm{~b} & 24 \mathrm{c} \\ \text { Lettuce } & 16 \mathrm{a} & 16 \mathrm{a} & 37 \mathrm{c} & 16 \mathrm{a} & 26 \mathrm{a} & 37 \mathrm{bc} \\ \text { Soybean } & 18 \mathrm{a} & 14 \mathrm{a} & 31 \mathrm{c} & 9 \mathrm{ab} & 17 \mathrm{ab} & 32 \mathrm{bc} \\ \text { Tomato } & 8 \mathrm{a} & 32 \mathrm{a} & 68 \mathrm{~b} & 0 \mathrm{ab} & 12 \mathrm{ab} & 32 \mathrm{bc} \\ \text { Wheat } & 6 \mathrm{a} & 19 \mathrm{a} & 65 \mathrm{~b} & 6 \mathrm{ab} & 15 \mathrm{ab} & 53 \mathrm{ab}\end{array}$

Root length (\% of growth inhibition)

$\begin{array}{lcccccc}\text { Maize } & 32 \mathrm{a} & 56 \mathrm{ab} & 86 \mathrm{a} & -15 \mathrm{c} & 43 \mathrm{a} & 80 \mathrm{a} \\ \text { Cucumber } & -14 \mathrm{~b} & 8 \mathrm{c} & 1 \mathrm{c} & -22 \mathrm{c} & -15 \mathrm{~b} & -15 \mathrm{c} \\ \text { Lettuce } & 20 \mathrm{ab} & 25 \mathrm{c} & 45 \mathrm{~b} & 32 \mathrm{a} & 35 \mathrm{a} & 47 \mathrm{c} \\ \text { Soybean } & 15 \mathrm{ab} & 19 \mathrm{c} & 56 \mathrm{~b} & 5 \mathrm{~b} & 27 \mathrm{a} & 59 \mathrm{~b} \\ \text { Tomato } & -2 \mathrm{ab} & 43 \mathrm{bc} & 51 \mathrm{~b} & 2 \mathrm{bc} & 30 \mathrm{a} & 42 \mathrm{c} \\ \text { Wheat } & 22 \mathrm{ab} & 72 \mathrm{a} & 84 \mathrm{a} & -5 \mathrm{~b} & 35 \mathrm{a} & 49 \mathrm{c}\end{array}$

Root dry weight (\% of growth inhibition)

$\begin{array}{lcccccc}\text { Maize } & 20 \mathrm{ab} & 34 \mathrm{~b} & 78 \mathrm{~b} & -12 \mathrm{ab} & 18 \mathrm{ab} & 70 \mathrm{~b} \\ \text { Cucumber } & -9 \mathrm{~b} & 32 \mathrm{~b} & 54 \mathrm{c} & -20 \mathrm{~b} & -7 \mathrm{~b} & 47 \mathrm{c} \\ \text { Lettuce } & 40 \mathrm{a} & 33 \mathrm{~b} & 60 \mathrm{c} & 20 \mathrm{a} & 47 \mathrm{a} & 67 \mathrm{~b} \\ \text { Soybean } & 30 \mathrm{ab} & 73 \mathrm{a} & 94 \mathrm{a} & 2 \mathrm{ab} & 63 \mathrm{a} & 94 \mathrm{a} \\ \text { Tomato } & -8 \mathrm{~b} & 46 \mathrm{ab} & 62 \mathrm{c} & 0 \mathrm{ab} & 31 \mathrm{ab} & 54 \mathrm{bc} \\ \text { Wheat } & 13 \mathrm{~b} & 45 \mathrm{ab} & 67 \mathrm{bc} & -17 \mathrm{~b} & 26 \mathrm{ab} & 64 \mathrm{~b}\end{array}$

${ }^{*}\left[\left(\right.\right.$ Growth $_{\text {control }}-$ Growth $\left._{\text {test }}\right) /\left(\right.$ Growth $\left.\left._{\text {control }}\right)\right] \times 100$, where Growth $_{\text {control }}=$ mean of growth of the control seedlings, Growth $_{\text {test }}=$ mean of growth of the test seedlings. Minus sign indicates that growth of the seedling was not inhibited compared with the control.

"Means of duplicates. Values within a column not sharing a letter are significantly different according to T-test (LSD, $\mathrm{P}=0.05$ ). 


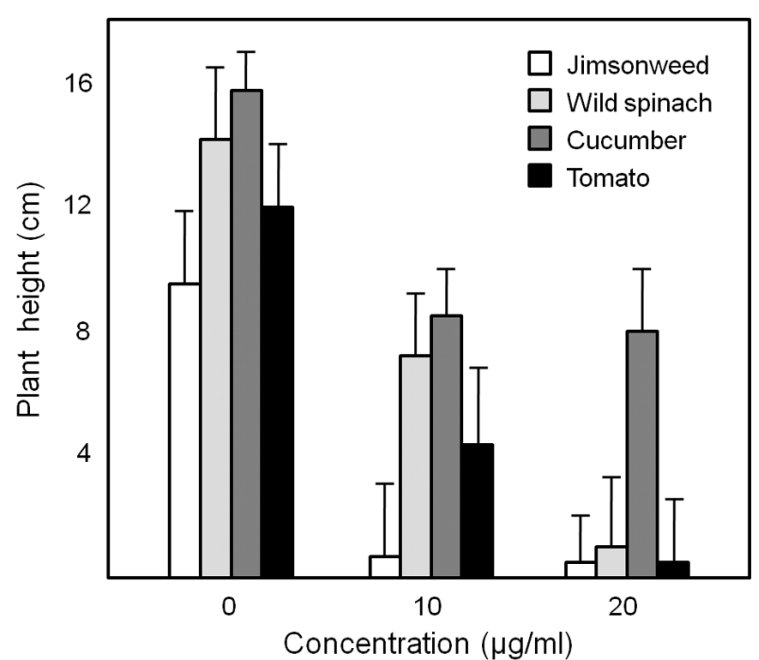

Fig. 3. Growth inhibition of weeds and vegetable plants by apicidin. Apicidin dissolved in 1\% methanol was applied on 2week-old plants, and plant height was measured 14 days after treatment.

was significantly affected by apicidin but root length of all plants except for maize looked comparable to that of the negative control. At this concentration, negative effect of apicidin $\mathrm{D}_{2}$ was weaker than that of apicidin in most cases (Table 1). At $20 \mu \mathrm{g} / \mathrm{ml}$, all plants and traits, except the root length of cucumber, were significantly affected by apicidins (Table 1). Although the root length was less affected by apicidins, root development such as root hair and spreading of roots were severely inhibited (data not shown). The phytotoxicity of apicidin was weaker than that of T-2 toxin, DON, 15-ADON and HC-toxin, which exhibited phytotoxic activity at concentration $1-10 \mu \mathrm{g} / \mathrm{ml}$ and inhibited root growth severely (Abbas et al., 2001; Desjardins, 2006).

Phytotoxicity of apicidins on weeds and vegetables. At $10 \mu \mathrm{g} / \mathrm{ml}$, phytotoxic symptoms appeared in all tested plants within 1-2 days after treatment with apicidins. The symptoms included chlorosis and necrosis on leaves, distortion of leaf shape, and growth inhibition (data not shown). Especially in tomato and jimsonweed, a severe damage occurred in the basal part of stems followed by rotting, and plants were fallen down to the ground. However, other plants recovered from the damages within a week. In cucumber, chlorosis, necrosis, leaf rolling, and stunting occurred on older leaves within 2 days after treatment. Leaf shape distortion was observed on immature leaves, but no mortality was observed in cucumber. The heights of wild spinach, cucumber, and tomato were greatly reduced as compared with the control (Fig. 3). Apicidin $\mathrm{D}_{2}$ also caused similar damages, but its phytotoxicity was less than that of apicidin (data not shown). At $20 \mu \mathrm{g} / \mathrm{ml}$, only cucumber survived after treatment, but the height of cucumber was severely reduced. Jimsonweed, wild spinach, and tomato were completely destroyed. Apicidin $\mathrm{D}_{2}$ showed a similar pattern of phytotoxic damages on these plants, but took a longer period to cause those damages (data not shown).

In conclusions, we determined that an apicidin-producing strain KCTC16676 belongs to the F. semitectum, improved the extraction procedure to enhance the yield and purify of apicidin, and showed phytotoxicity of apicidins. In many cases, genes required for the secondary metabolites of fungi including Fusarium spp. are clustered in the genome, and the expression of those genes is controlled by transcription factor(s) that are also located in the cluster (Lee et al., 2001; Kim et al., 2005). We hypothesize that the genes involved in apicidin biosynthesis are clustered. Attempts to find such genes are in progress through the use of both forward and reverse genetics approaches. Identification of transcription factor(s) controlling apicidin biosynthesis genes will help us overproduce apicidin by upregulating the downstream genes in KCTC16676.

\section{Acknowledgments}

This study was supported by the Korea Research Foundation Grant funded by the Korean Government (MOEHRD) (KRF-2006-005-J04701) and by a grant (CG1411) from the Crop Functional Genomics Center of the $21^{\text {st }}$ Century Frontier Research Program funded by the Korean Ministry of Education, Science and Technology.

\section{References}

Abbas, H. K., Gronwald, J. W., Plaisance, K. L., Paul, R. N. and Lee, Y.-W. 2001. Histone deacetylase activity and phytotoxic effects following exposure of duckweed (Lemna pausicostata L.) to apicidin and HC-toxin. Phytopathology 91:1141-1148.

Darkin-Rattray, S. J., Gurnett, A. M., Myers, R. W., Dulski, P. M., Crumley, T. M., Alloco, J. J., Cannova, C., Meinke, P. T., Colletti, S. L., Bednarek, M. A., Sing, S. B., Goetz, M. A., Dombrowski, A. W., Plishgook, J. D. and Schmatz, D. M. 1996. Apicidin: A novel antiprotozoal agent that inhibits parasite histone deacetylase. Proc. Natl. Acad. Sci. USA 93:1314313147.

Desjardines, A. E. 2006. Fusarium Mycotoxins: Chemistry, Genetics, and Biology. APS Press, St. Paul, MN, USA.

Geiser, D., Jimenez-Gasco, M., Kang, S., Makalowska, I., Veeraraghavan, N., Ward, T., Zhang, N., Kuldau, G. and O'Donnell, K. 2004. FUSARIUM-ID v.1.0: a DNA sequence database for identifying Fusarium. Eur. J. Plant Pathol. 110:473479.

Gerlach, W. and Nirenberg, H. I. 1982. The genus Fusarium - a pictorial atlas. Mitt. Biol. Bundes. Land- Forst. (Berlin Dahlem) 209:1-406.

Hirota, A., Suzuki, A., Aizawa, K. and Tamura, S. 1973. Structure of Cyl-2, a novel cyclopeptide from Cylindrocladium scopar- 
ium. Agric. Biol. Chem. 37:955-956.

Hong, J., Ishihara, K., Yamaki, K., Hiraizumi, K., Ohno, T., Ahn, J. W., Zee, O. and Ohuchi, K. 2003. Apicidin, a histone deacetylase inhibitor, induces differentiation of HL-60 cells. Cancer Lett. 189:197-206.

Kawai, M., Jasensky, R. D. and Rich, D. H. 1983. Conformational analysis by NMR spectrometry of the highly substituted cyclic tetrapeptides, chlamydocin and Ala-chlamydocin. Evidence for a unique amide bond sequence in dimethyl-d sulfoxidy. $J$. Am. Chem. Soc. 105:4456-4462.

Kim, Y.-T., Lee, Y.-R., Jin, J., Han, K.-H., Kim, H., Kim, J.-C., Lee, T., Yun, S.-H and Lee, Y.-W. 2005. Two different polyketide synthase genes are required for synthesis of zearalenone in Gibberella zeae. Mol. Microbiol. 58:11021113.

Kumar, S., Tamura, K. and Nei, M. 2004. MEGA3: Integrated software for molecular evolutionary genetics analysis and sequence alignment. Brief. Bioinform. 5:150-163.

Lee, T., Oh, D-W., Kim, H.-S., Lee, J., Kim, Y.-H., Yun, S.-H. and Lee, Y.-W. 2001. Identification of deoxynivalenol- and nivalenol-producing chemotypes of Gibberella zeae by using PCR. Appl. Environ. Microbiol. 67:2966-2972.

Leslie, J. F. 2001. Population genetics level problems in the Gibberella fujikuroi species complex. Pages 113-121 in: Fusarium: Paul E. Nelson Memorial Symposium. Summerell, B. A., Leslie, J. F., Backhouse, D., Bryden, W. L. and Burgess, L. W. eds. American Phytopathological Society, St. Paul, MN.

Leslie, J. F. and Summerell, B. A. 2006. The Fusarium Laboratory Manual. Blackwell Publishing, Ames, IA, USA.

Liesch, J. M., Sweeley, C. C., Staffeld, G. D., Anderson, M. S., Weber, D. J. and Scheffer, R. P. 1982. Structure of HC-toxin, a cyclic tetrapeptide from Helminthosporium carbonum. Tetrahedron 38:45-48.

Nelson, P. E., Toussoun, T. A. and Marasas, W. F. O. 1983. Fusarium species: An illustrated manual for identification. Pennsylvania State University, University Park.

Nirenberg, H. I. and O’Donnell, K. 1998. New Fusarium species and combinations within the Gibberella fujikuroi species com- plex. Mycologia 94:434-458.

O’Donnell, K., Kistler, H. C., Tacke, B. K. and Ploetz, R. C. 1998. Multiple evolutionary origins of the fungus causing Panama disease of banana: Concordant evidence from nuclear and mitochondrial gene genealogies. Proc. Natl. Acad. Sci. USA 95:2044-2049.

Park, J.-S., Lee, K.-R., Kim, J.-C., Lim, S.-H., Seo, J.-A. and Lee, Y.-W. 1999. A hemorrhagic factor (apicidin) produced by toxic Fusarium isolates from soybean seeds. Appl. Environ. Microbiol. 65:126-130.

Saitou, N. and Nei, M. 1987. The neighbor-joining method: a new method for reconstructing phylogenetic trees. Mol. Biol. Evol. 4:406-425.

Singh, S. B., Zink, D. L., Liesch, J. M., Mosley, R. T., Dombrowski, A. W., Bills, G. F., Darkin-Rattray, S. J., Schmatz, D. M. and Goetz, M. A. 2002. Structure and chemistry of apicidins, a class of novel cyclic tetrapeptides without a terminal alpha-keto epoxide as inhibitors of histone deacetylase with potent antiprotozoal activities. J. Org. Chem. 67:815-825.

Singh, S. B., Zink, D. L., Polishook, J. D., Dombrowski, A. W., Darkin-Rattray, S. J., Schmatz, D. M. and Goetz, M. A. 1996. Apicidins: Novel cyclic tetrapeptides as coccidiostats and antimalarial agents from Fusarium pallidoroseum. Tetrahedron Lett. 37:8077-8080.

Summerell, B. A., Salleh, B. and Leslie, J. F. 2003. A utilitarian approach to Fusarium identification. Plant Dis. 87:117-128.

Takayama, S., Lsogai, A., Nakata, M., Suzuki, H. and Susuki, A. 1984. Structure of Cyl-1, a novel cyclic tetrapetide from Cylindrocladium scoparium. Agric. Biol. Chem. 48:839-842.

Thompson, J. D., Higgins, D. G. and Gibson, T. J. 1994. Clustal $\mathrm{W}$ : improving the sensitivity of progressive multiple sequence alignment through sequence weighting, position-specific gap penalties and weight matrix choice. Nucleic Acids Res. 22:4673-4680.

Ueda, T., Takai, N., Nishida, M., Nasu, K. and Narahara, H. 2007. Apicidin, a novel histone deacetylase inhibitor, has profound anti-growth activity in human endometrial and ovarian cancer cells. Int. J. Mol. Med. 19:301-308. 